\title{
Multigene expression signatures in early hormone receptor positive HER 2 negative breast cancer
}

\author{
Tanja Ovcaricek ${ }^{1}$ Iztok Takac ${ }^{2,3}$, Erika Matos ${ }^{1}$ \\ ${ }^{1}$ Department of Medical Oncology, Institute of Oncology Ljubljana, Ljubljana, Slovenia
${ }^{2}$ Division of Gynecology and Perinatology, University of Maribor Clinical Centre, Maribor, Slovenia
${ }^{3}$ Department of Gynecology and Obstetrics, Faculty of Medicine, University of Maribor, Maribor, Slovenia
}

Radiol Oncol 2019; 53(3): 285-292.

Received 3 January 2019

Accepted 20 July 2019

Correspondence to: Assoc. Prof. Erka Matos, M.D., Ph.D., Department of Medical Oncology, Institute of Oncology Ljubljana; Zaloška 2, SI-1000 Ljubljana, Slovenia. Phone: +386 15879 971; Fax: +386 15879 305; E-mail: ematos@onko-i.si.

Disclosure: No potential conflicts of interest were disclosed.

Background. The standard treatment of hormone receptor positive, HER2 negative early breast cancer (BC) is surgery followed by adjuvant systemic therapy either with endocrine therapy alone or with the addition of chemotherapy followed by endocrine therapy. Adjuvant systemic therapy reduces the risk of recurrence and death from BC. Whether an individual patient will benefit from adjuvant chemotherapy is an important clinical decision. Decisions that rely solely on clinical-pathological factors can often lead to overtreatment. Multigene signatures represent an important progress in optimal selection of high risk patients that might benefit from the addition of chemotherapy to adjuvant endocrine therapy.

Conclusions. Several signatures are already commercially available and also accepted by international guidelines. Oncotype DX and MammaPrint have been most extensively validated and supported by level IA evidence.

Key words: hormone receptor positive HER-2 negative early breast cancer; adjuvant systemic therapy; multigene signatures

\section{Introduction}

Breast cancer (BC) is the most common cancer in women in Slovenia and worldwide. More than 1300 women in Slovenia were diagnosed with breast cancer in 2015. ${ }^{1}$ Approximately two thirds of BC are hormone receptor positive. ${ }^{2}$ The standard treatment of hormone receptor positive, HER2 negative (HR+HER2-) early BC is surgery followed by adjuvant systemic therapy either with endocrine therapy alone or with the addition of chemotherapy followed by endocrine therapy. Adjuvant systemic therapy reduces the risk of recurrence and death from BC by approximately one third.,4 Whether an individual patient will benefit from adjuvant chemotherapy is an important decision. Classical clinical-pathological parameters (tumor size, nodal status, histological grade, proliferation index, age, hormone receptor status and menopausal status) are helpful in defining the risk of recurrence. However, these parameters do not take into account an individual biology of a tumor and substantial number of patients with early BC are thus over-treated and exposed to toxic effects of chemotherapy without any benefit. ${ }^{5}$ Several multigene expression signatures have been developed to better prognosticate disease outcome.

Several of these signatures are commercially available and accepted by international guidelines, including the Oncotype DX recurrence score (Genomic Health), PAM50 Prosigna risk of recurrence (NanoString), Breast Cancer Index (BCI) (bioTheranostics), EndoPredict (MyriadGenetics), and MammaPrint (Agendia BV). Oncotype DX 
and MammaPrint have been most extensively validated, including in prospective randomized trials, TAILOR $x$ and MINDACT and are therefore most commonly used. They are commercially available; however they are not reimbursed in Slovenia. ${ }^{6-9}$ Here, we focused on Oncotype DX and MammaPrint as other assays are much less frequently used in routine clinical practice.

\section{Oncotype DX}

Oncotype DX is performed on RNA extracted from formalin-fixed paraffin-embedded tumor tissue using quantitative real-time reverse transcriptase polymerase chain reaction (qRT-PCR) and contains 5 reference genes and 16 cancer-related genes. The recurrence score (RS) is the result of mathematical formula of the weighted expression of each gene. The cut-off points are divided into 3 categories: low, intermediate and high risk. ${ }^{10,11}$

Its prognostic value was first evaluated on archived tissue from HR+HER2- lymph node negative patients from NSABP B-14 study and was confirmed later on in other studies. ${ }^{12,13}$ Paik et al., demonstrated its ability to predict chemotherapy sensitivity in lymph node negative HR+HER2early BC patients. Patients with high RS had ben-

TABLE 1. Recurrence score (RS) distribution among studies that validated Oncotype DX in node positive breast cancer ( $N=9055)$

\begin{tabular}{lccc}
\hline Study & RS low (\%) & RS intermediate (\%) & RS high (\%) \\
\hline SWOG S8814 & 40 & 28 & 32 \\
TransATAC & 52 & 31 & 17 \\
SEER & 57 & 36 & 7 \\
Clait & 53 & 36 & 10 \\
PlanB & 19 & 63 & 19 \\
\hline
\end{tabular}

First four of the studies used standard cut-offs (RS $<18,18-30, \geq 31$ ), the PlanB study used nonstandard cut-offs (RS $<12,12-25,>25$ ), the same as TAILORx, RXPONDER study.

TABLE 2. Estimated survival rates according to recurrence score (RS) and treatment assigned in the intention to treat population (TAILORx trial)

\begin{tabular}{|c|c|c|}
\hline & 9-year DFS (\%) & 9-year OS (\%) \\
\hline $\begin{array}{l}\text { Low risk; } \mathrm{RS} \leq 10, \mathrm{~N}=1619 \text { (16.7\%) } \\
\text { endocrine therapy }\end{array}$ & 84 & 93.7 \\
\hline $\begin{array}{l}\text { Intermediate risk; } \text { RS } 11-25, N=3399 \\
(34.9 \%) \text { endocrine therapy }\end{array}$ & 83.3 & 93.9 \\
\hline $\begin{array}{l}\text { Intermediate risk; RS } 11-25, \mathrm{~N}=3312(34 \%) \\
\text { chemotherapy and endocrine therapy }\end{array}$ & 84.3 & 93.8 \\
\hline $\begin{array}{l}\text { High risk; } \mathrm{RS} \geq 26, \mathrm{~N}=1389 \text { (14.4\%) } \\
\text { chemotherapy and endocrine therapy }\end{array}$ & 75.7 & 89.3 \\
\hline
\end{tabular}

DFS = disease free survival; ITT = intention to treat; $\mathrm{N}=$ number; OS = overall survival; $\mathrm{RS}=$ recurrence score efited from chemotherapy, with the 10-year metastasis rate being decreased by $27.6 \%$ for those patients who received adjuvant chemotherapy. In contrast, there was no benefit of adding chemotherapy to patients with low RS. ${ }^{10-13}$ The evidence is less strong for patients with lymph node positive disease. Five studies are relevant in this context: South West Oncology Group study (SWOGS8814), TransATAC, West German Cancer Group (WSG) PlanB study and two population based registries. ${ }^{10,14-18}$ The results of these studies consistently show that a considerable percent of patients have a low-risk genomic signature despite positive nodal status and thus nodal positivity should not uniformly lead to decision of adding adjuvant chemotherapy to endocrine therapy (Table 1).

SWOG S8814 study data represents the strongest evidence available thus far that Oncotype DX predicts chemotherapy benefit in lymph node positive patients. The study was prospectively planned to examine this association and was applied to a randomised phase 3 trial with an endocrine therapy alone or in combination with chemotherapy. The test for interaction of chemotherapy with RS was significant. The study found significant improvement in disease free survival (DFS) when chemotherapy was added to endocrine therapy in patients with high genomic risk ( $R S \geq 31$ ) (HR: 0.59, $p=0.003$ ) and no improvement in DFS for adding chemotherapy to endocrine therapy for patients with low RS $(<18) \cdot{ }^{10}$

Until the results of TAILORx (Trial Assigning IndividuaLized Options for Treatment) study which aimed to answer whether chemotherapy would reduce the risk for recurrence in intermediate risk group this was unclear. In TAILORx study different cut-offs were used as initially set. ${ }^{11,12}$ This study was designed to test whether chemotherapy is beneficial for women with intermediate RS (RS 11-25). 10253 women with HR+HER2-, node negative $\mathrm{BC}$ who met the criteria for consideration of adjuvant chemotherapy (tumor size $11-50 \mathrm{~mm}$, or more than $5 \mathrm{~mm}$ with additional pathological unfavourable characteristics such as intermediate/high nuclear grade and presence of lymphovascular invasion) were enrolled. Women were assigned to one of four treatment groups on the basis of RS. Those with a RS $\leq 10$ were assigned to receive endocrine therapy only, and women with RS $\geq 26$ were assigned to receive chemotherapy plus endocrine therapy. Women with intermediate score of 11 to 25 were randomized to receive either endocrine therapy alone or in combination with chemotherapy. The study found no improve- 
ment in DFS when chemotherapy was added to endocrine therapy in intermediate risk group (HR for DFS for endocrine vs endocrine and chemotherapy: 1.08 ; $95 \mathrm{CI}, 0.94-1.24, \mathrm{p}=0.26) .{ }^{13}$ Estimated survival rate according to risk group are depicted in Table 2.

Exploratory analysis was conducted to search for any subgroups who might derive some benefit from chemotherapy in the intermediate risk group. An interaction between age and RS was found $(p=0.004)$, with some benefit of chemotherapy in younger patient population ( $<50$ years) with RS 16 to 25 . In this group of patients there were $2 \%$ fewer distant recurrences when chemotherapy was added for RS 16-20, and 7\% fewer for RS 21-25. ${ }^{13}$ This information should be discussed with individual patients who fit in either category. The results of TAILORx suggest that Oncotype DX may identify up to $85 \%$ of women with HR+HER2- early BC older than 50 years with RS $\leq 25$ and $40 \%$ of younger women ( $\leq 50$ years ) with a RS $\leq 15$ who can safely be spared adjuvant chemotherapy. ${ }^{13}$

We conclude that for patients with HR+HER2lymph node negative BC patients older than 50 years RS 25 or more should be considered a cut-off point for adjuvant chemotherapy recommendation, whereas younger patients (less than 50 years) should be informed about the modest benefit of adding adjuvant chemotherapy at lower cut-off point (RS 16). For lymph node positive patients, the cut-off is less clear. Results from the published studies suggest that patients with HR+HER2lymph node positive BC and RS $<18$ do not benefit from adjuvant chemotherapy and for patients with $R S \geq 31$ chemotherapy should be considered. ${ }^{10,16-18}$ The results of the ongoing prospective trial RxPONDER (Treatment for Positive Node, Endocrine Responsive Breast Cancer) will give us further insight into RS cut-off point for chemotherapy benefit in lymph node positive BC. ${ }^{19}$

\section{MammaPrint}

MammaPrint was developed by the Netherlands Cancer Institute group using DNA microarray analysis of gene expression arrays on frozen tissue from 78 primary BC tumors. ${ }^{20}$ The gene expression panel contains 70 genes correlated with evading apoptosis, self-sufficiency in growth signals, insensitivity to anti-growth signals, limitless replicative potential, tissue invasion and metastasis and sustained angiogenesis. ${ }^{21} \mathrm{~A}$ mathematical model is used to calculate score that stratifies patients into low- and high risk group. ${ }^{20,22}$
The first retrospective validation of MammaPrint was performed by van de Vijver and colleagues, on a consecutive series of 295 BC tumors (lymph node positive and negative). MammaPrint accurately distinguished a good-prognosis group which had a 10-year overall survival of $95 \%$ from a poor-prognosis group which had a 10-year overall survival of $55 \%(p \leq 0,001) .22,23$ However, there was one major disadvantage for the implementation of MammaPrint and this was the requirement for good quality RNA from fresh frozen tissue specimen. Improvements in RNA processing have enabled microarray diagnostics for formalinfixed, paraffin-embedded (FFPE) tissue. Later on, MammaPrint was successfully translated to FFPE on 580 tumor samples. ${ }^{24}$

RASTER trial was the first prospective phase 3 trial assessing MammaPrint. This study confirmed the feasibility of collecting good quality fresh frozen tissue for analysis and confirmed prognostic value of MammaPrint in lymph node negative T1-T3 BC for distant recurrence and also compared it with Adjuvant!Online (AOL). ${ }^{25,26}$ Other studies further investigated MammaPrint in patients with lymph node positive BC. In the study of Mook et al., the prognostic value of MammaPrint was demonstrated to be superior to classical clinical-pathological factors in patients with 1-3 positive lymph nodes for predicting breast cancer specific survival (BCSS). ${ }^{27}$

Prospective, randomized, phase 3, MINDACT study (Microarray in Node-Negative and 1 to 3 Positive Lymph Node Disease May Avoid Chemotherapy) was performed to test the clinical utility of the addition of the MammaPrint to standard clinical-pathological criteria in selecting patients for adjuvant chemotherapy. ${ }^{28-30}$ The study enrolled 6693 women with T1-T3 operable tumors, lymph node negative (app 80\%) and positive (one to three positive lymph nodes). It was performed using fresh frozen tissue. MammaPrint was used to determine genomic risk and AOL version 8.0 was used to determine clinical risk. Low clinical risk was defined by low grade and tumor size $<=3 \mathrm{~cm}$, intermediate grade and tumor size $<=2 \mathrm{~cm}$, and high grade and tumor size $<=1 \mathrm{~cm}$, in lymph node negative patients, whereas only low grade and tumor size $<=2 \mathrm{~cm}$ were considered low clinical risk in lymph node positive patients (Table 3 ). The patients were divided into four main groups, according to their clinical and genomic risk. Women at low clinical and genomic risk did not receive chemotherapy, whereas those at high clinical and genomic risk did receive such therapy. Patients 
TABLE 3. Definition of high clinical risk tumors in MINDACT trial according to lymph node status

\begin{tabular}{ll}
\hline Lymph node negative $(\mathrm{N}=\mathbf{2 1 1 4}, \mathbf{6 4 \%})$ & Lymph node positive $(\mathrm{N}=\mathbf{1 2 1 4}, \mathbf{3 6 \%})$ \\
\hline G1, tumor size $>3 \mathrm{~cm}$ & G1, tumor size $>2 \mathrm{~cm}$ \\
G2, tumor size $>2 \mathrm{~cm}$ & G2, any size \\
G3, tumor size $>1 \mathrm{~cm}$ & G3, any size \\
\hline
\end{tabular}

TABLE 4. Distribution of risk groups according to clinical and genomic prediction and treatment assigned in MINDACT trial $(\mathrm{N}=6693)$

\begin{tabular}{lcc}
\hline Risk groups & Percentage N (\%) & Treatment regimen \\
\hline $\begin{array}{l}\text { Low clinical and low } \\
\text { genomic }\end{array}$ & $2745(41.0)$ & no chemotherapy \\
$\begin{array}{l}\text { Low clinical and high } \\
\text { genomic } \\
\text { High clinical and low } \\
\text { genomic }\end{array}$ & $592(8.8)$ & $\begin{array}{c}\text { randomization: } \\
\text { chemotherapy vs no }\end{array}$ \\
$\begin{array}{l}\text { High clinical and high } \\
\text { genomic }\end{array}$ & $1550(23.2)$ & $\begin{array}{c}\text { randomization: } \\
\text { chemotherapy vs no }\end{array}$ \\
\hline
\end{tabular}

TABLE 5. Estimated survival rates according to risk groups and treatment assigned in the intention-to-treat population

\begin{tabular}{lcc} 
& 5-year DFS (\%) & 5-year OS (\%) \\
\hline $\begin{array}{l}\text { c-low/g-low } \\
\text { C-high/g-low: } \\
\text { chemotherapy vs no chemotherapy }\end{array}$ & 92.8 & 98.4 \\
$\begin{array}{l}\text { c-low/g-high: } \\
\text { chemotherapy vs no chemotherapy }\end{array}$ & 92.9 vs. 90.1 & 98.4 vs. 97.0 \\
\begin{tabular}{l} 
C-high/g-high \\
\hline
\end{tabular} & 85.3 & 97.1 vs. 97.8 \\
\hline
\end{tabular}

$\mathrm{c}-$ low $/$ high $=$ clinical low $/$ high risk $;$ g-low $/$ high $=$ genomic low risk/high

with discordant results were randomized to receive or not receive adjuvant chemotherapy (Table 4). ${ }^{28-30}$

Among patients at low clinical and high genomic risk, those who were randomized on the basis of genomic risk and therefore received chemotherapy had similar outcomes compared to those who were randomized to no chemotherapy on the basis of clinical risk. ${ }^{28-30}$ Therefore, we can conclude that there is no use for MammaPrint risk assessment in patients with clinically low risk disease. Among patients at high clinical and low genomic risk, those who underwent randomization on the basis of clinical risk and received chemotherapy the DFS rate was 2.8 percentage points higher, and OS rate was 1.4 percentage points higher compared to those without chemotherapy. The study was not powered to assess the statisti- cal significance of these differences or to exclude the benefit of chemotherapy. ${ }^{28-30}$ But the results implicate that chemotherapy could be avoided in patients with high clinical and low genomic risk at a cost of the above mentioned differences and this should be discussed with a patient (Table 5). The use of MammaPrint in clinical high risk group would lead to a reduction in the use of adjuvant chemotherapy in $46.2 \%$ of patients. ${ }^{28-30}$ In addition to this, ultra-low threshold was identified, which defines patients with indolent disease behaviour whose long-term risk of death from breast cancer is extremely low after surgery alone without any systemic therapy. ${ }^{31}$

\section{Other multigene signatures}

Other prognostic multigene signatures have also been validated in clinical trials and some are recommended by international guidelines as well.

- EndoPredict: It is RNA-based and uses reverse transcriptase polymerase chain reaction of 12 genes to calculate prognostic score. It was validated retrospectively using prospectively collected data and tumor tissue from two Austrian Breast Cancer Study Group trials (ABCSG-6 and ABCSG-8). EndoPredict calculates a risk score, which can be used together with tumor size and nodal status for the calculation of a risk score (EPclin). Its applications include prediction of distant recurrence at 5 and 10 years in each individual patient and may add to decision about extended endocrine therapy. ${ }^{32,33}$

- Predictor Analysis of Microarray 50 (PAM50): PAM50 risk of recurrence score is a 50 gene test that uses microarray and quantitative reverse transcription polymerase chain reaction to provide a risk of recurrence score (ROR) that takes into account the PAM50 profile and clinical features of the patient, such as tumor size and proliferation score. ROR is used for prediction of individual risk of distant recurrence at 10 years. It was validated in lymph node negative as well as positive patients from ABCSG-8 and ATAC trial. The relationship between 10-year risk of distant recurrence and the ROR score differs markedly between node-negative and lymph-node positive patients (10- year risk of distant recurrence in low risk lymph node negative group was $4.9 \%$, while in lymph node positive group (1-2 positive lymph nodes) $12.3 \%$ ). Prosigna assay results are reported as ROR score from 0 to 100 in two ways, node-negative cancers are classified as low (0-40), intermediate (41-60), or high 
(61-100) risk and node-positive cancers are classified as low (0-40) or high (41-100) risk. ${ }^{34,35}$

- Breast Cancer Index (BCI): The BCI is a score calculated according to 2-gene group expression, the 2-gene ratio HOXB13:IL17BR (H:I ratio) and the expression of 5 proliferation genes known as molecular grade index (MGI score). The TransATAC and the Stockholm trials in which patients received adjuvant endocrine therapy, provided the clinical validation. In postmenopausal patients with HR+HER2-, lymph node negative $\mathrm{BC}$ it might serve as a predictive test for the likelihood of benefit from extended adjuvant endocrine therapy. ${ }^{36-38}$ This test has no FDA approval.

\section{Discussion}

Prognosis of patients with early BC has improved significantly in the last two decades mostly due to effective adjuvant systemic treatment.,4 However, about two-thirds of patients with lymph nodenegative $\mathrm{BC}$ are cured by loco-regional treatment already and they represent more than $50 \%$ of early BC patients. ${ }^{39}$ Additionally $25-30 \%$ of patients with 1 to 3 positive lymph nodes remain free of distant metastases without adjuvant chemotherapy. ${ }^{40}$ Therefore, these patients might safely be spared from toxic effects of chemotherapy. Based solely on traditional clinical-pathological characteristics it is not possible to reliably identify the high risk patients that would potentially benefit from adjuvant chemotherapy. Multigene signatures represent an important progress in optimal selection of these patients. ${ }^{41}$ Their clinical utility for risk prediction was confirmed in different clinical studies. Oncotype DX and MammaPrint are the most extensively studied among them.

Oncotype DX and MammaPrint, both of them have demonstrated efficacy for evaluation of recurrence risk in women with stage I and II BC with up to 3 positive lymph nodes. ${ }^{13,29}$ But from the published studies and clinical use, we can draw out some differences. MammaPrint provides a binary result for prognosis as low- and high-risk, whereas Oncotype DX provides also intermediate risk, which keeps clinicians in uncertainty. TAILORx study prospectively addressed this issue and provides strong evidence that chemotherapy is of limited benefit in this patient subgroup. Nevertheless, there are some patients (younger than 50 with RS 16-25) in the intermediate risk group that might derive some benefit from adjuvant chemotherapy. There were also some crucial differences in the in- clusion criteria for the two studies testing the utility of MammaPrint and Oncotype DX.13,29 According to these studies MammaPrint can be applied to a wider variety of patients, namely those with any ER status, largely as a result of gene selection the signature includes (mostly estrogen signalling genes in Oncotype DX), but this is of limited clinical utility. ${ }^{28}$ While MammaPrint was validated also on lymph node positive BC patients (1-3positive lymph nodes), the evidence for the use of Oncotype DX in these patients population is weaker. ${ }^{9}$ We are awaiting the results of RxPONDER trial, which will provide further information on this topic. ${ }^{19} \mathrm{On}$ the other hand, Oncotype DX is the only multigene signature that has both, prognostic and predictive value for chemotherapy sensitivity. The idea that prediction of treatment benefit can be concluded from prognosis is flawed and a statistical test for an interaction between a biomarker and treatment is necessary to determine biomarkers' predictive utility. 5,42,43 The findings from NSABP-B20, TAILORx, SWOG 8814 trials have confirmed a clear interaction between chemotherapy benefit and Oncotype DX result. ${ }^{10,12,13}$

One of the most important benefits of genomic testing is the selection of patient in which treatment with adjuvant chemotherapy can be safely omitted. However, the added value of multigene signatures for de-escalation of chemotherapy to no chemotherapy in daily clinical practice is still unclear. Eightyfive percent of older ( $>50$ years) and $40 \%$ of younger patients in TAILORx trial and $46 \%$ of clinical high risk patients in MINDACT trial could be spared the addition of adjuvant chemotherapy. However, these numbers cannot be compared directly because the design and inclusion criteria for these two studies were different. The utility of multigene signatures was considered in all patients with tumors greater than $1 \mathrm{~cm}$ (or $5 \mathrm{~mm}$ and adverse characteristics) in TAILORx, while MammaPrint use was meaningful only in clinical high risk patients. Also the number of patients classified as low genomic risk varied significantly between the two tests; Oncotype DX identified only about $17 \%$ of patients as low genomic risk, and $69 \%$ as intermediate, whereas MammaPrint identified $64 \%$ in the whole population and $46 \%$ in clinical high risk population as low genomic risk. ${ }^{13,30}$ If MINDACT criteria for definition for high clinical risk were applied to TAILORx population, $3.5 \%$ of patients with genomic low risk (low RS), $17.4 \%$ in intermediate RS and only $7.9 \%$ in high RS fit criteria for clinical high risk.

Some information on de-escalation of chemotherapy prescription by the use of multigene signa- 
tures might be drawn from large studies performed on real-life patients cohorts. Use of Oncotype DX and MammaPrint was evaluated on 476,128 women from the National Cancer Database. Multigene signature use was associated with a significant decrease in rate of chemotherapy administration ( 24.6 vs. $37.2 \%$ ). Chemotherapy was administered to a higher percentage of patients undergoing MammaPrint compared to Oncotype DX ( $41.3 \%$ vs. $23.4 \%, \mathrm{p}<0.001) .{ }^{44}$

Retrospective analysis that matched Oncotype DX results with SEER registry clinical data for over 40,000 node negative HR+HER-2-patients did not show lower chemotherapy use in real-life patients who had Oncotype DX performed compared to those without (22.7\% vs. $22 \%$ ), although Oncotype DX was prognostic for five-year breast-cancer-specific mortality. ${ }^{45}$ Also in some other retrospective population-based cohorts, the use of multigene signatures did not lead to a reduction of chemotherapy use. ${ }^{46-48}$

Currently there is no data on which test provides the best prognostic information. In a systematic review which included 22 studies for Oncotype DX, 4 for MammaPrint, and 1 for both Prosigna and EndoPredict. The hypothetical application of chemotherapy for the same patient, with and without the results of the multigene test was analysed. A decrease in chemotherapy use for all tests was confirmed. When the results were pooled per assay, the decrease in chemotherapy to no chemotherapy was $45.7 \%$ for Oncotype DX and 32.2\% for MammaPrint. ${ }^{49}$

Direct comparison of 6 multigene signatures (including Oncotype DX, EndoPredict, BCI, PAM50, Clinical Treatment Score (CTS) and 4-marker immunohistochemical score (IHC4) for prediction of distant recurrence in addition to clinical information was performed in the population of TransATAC trial. MammaPrint was not includ-

TABLE 6. Recommendations for the use of multigene signatures in ER-positive, HERnegative breast cancer patients by different expert panels

\begin{tabular}{|c|c|c|c|c|c|}
\hline TEST & ASCO & $\mathrm{NCCN}$ & ESMO* & $\begin{array}{l}\text { St Gallen } \\
\text { Group** }\end{array}$ & EGTM \\
\hline Oncotype DX & Ln - , strong & $\begin{array}{l}\operatorname{Ln}-, 1 \\
\operatorname{Ln}+, 2 A\end{array}$ & IB & Yes & $\operatorname{Ln}+/-$ \\
\hline MammaPrint & $\begin{array}{l}\text { Ln -, strong } \\
\operatorname{Ln}+\text {, moderate }\end{array}$ & $\operatorname{Ln}-/+, 1$ & IB & Yes & $\operatorname{Ln}+/-$ \\
\hline PAM50 & Ln -, moderate & $\mathrm{Ln}-/+, 2 \mathrm{~A}$ & IB & Yes & $\operatorname{Ln}+/-$ \\
\hline EndoPredict & Ln -, moderate & $\operatorname{Ln}-/+, 2 A$ & IB & Yes & $\operatorname{Ln}+/-$ \\
\hline $\mathrm{BCl}$ & Ln -, moderate & $\operatorname{Ln} N R, 2 A$ & no & Yes & Ln - \\
\hline
\end{tabular}

$\mathrm{Ln}=$ lymph nodes; $\mathrm{NR}=$ not reported ed in this study. All signatures provided similar prognostic information during the first 5 years of follow-up for lymph node negative patients, but PAM50, BCI, and EndoPredict were significantly more prognostic during 5-10 years, which may indicate they have molecular components that are more specifically prognostic for late recurrence, such as ER-signalling pathway. For women with 1 to 3 positive nodes, the independent prognostic strength of all of them was weaker..$^{50}$ The prospective OPTIMA trial compared performance of Oncotype DX, MammaPrint, PAM50 and IHC4 for evaluation of individual patient risk. Among these signatures a marked disagreement when applied to the same patient was found in the majority $(60.6 \%)$ of tumors. From a biological perspective, it is entirely predictable that tests that measure different genes give dissimilar results. However, the proportions of patients identified as low, intermediate, or high risk were broadly similar irrespective of which test was used (low/intermediate risk: $82.1 \%$ for Oncotype DX, 72.0\% for IHC4, 65.6\% for Prosigna and $61.4 \%$ for MammaPrint). ${ }^{51}$ No patient outcome data were available at the time of analysis and therefore we cannot draw any conclusion about the comparison on clinical utility of these tests. The performance of multiple gene signatures in one patient is not feasible in clinical practice.

Based on this, multigene expression signatures are endorsed as validated decision making tool in early BC by different international guidelines. However, there are differences regarding credibility of different multigene signatures given the number and quality of studies differ considerably among them (Table 6). St Gallen recommendation support the use of multigene signatures, however the recommendation is broad and does not support specific assay. The St Gallen Panel does not uniformly endorse the use of multigene signatures in node positive cases, although the panel agrees that they offer additional prognostic information in these patients. The same is true for ESMO guidelines which support multigene signature use (except for BCI) and are not specific as to the lymph node status. ${ }^{2,8}$ All multigene signatures are recommended for use in HR+HER2- lymph node negative or positive BC by the European Group on Tumor Markers (EGTM), except for BCI. ${ }^{6}$ Oncotype DX is the only multigene signature assigned with NCCN category of preference as preferred in lymph node negative patients (category 1 evidence) and is the only signature with predictive value, MammaPrint has category 1 recommendation as prognostic for lymph node negative and positive patients. ${ }^{9}$ 
ASCO guidelines strongly recommend the use of Oncotype DX and MammaPrint in lymph node negative patients and MammaPrint is the only multigene signature endorsed by ASCO guidelines for lymph node positive patients (Table 6). ${ }^{7}$

At the time being we do not know which of the multigene signature has the most accurate prognostic value. However, Oncotype DX and MammaPrint have currently the most extensive level of evidence and are most widely used. The decision to choose one of them is in most cases based on individual oncologist experiences. Nevertheless, price and accessibility might be also important since in many European countries as well in Slovenia the test is still not covered by the insurance companies. Future studies and data from national and institutional patient's registries will help us to more optimally guide the use of appropriate multigene signatures and subgroups for testing and give us information on long-term outcome in order to determine the place of these assays in daily clinical practice.

\section{Conclusions}

Multigene signature assays provide prognostic information that augments the one from clinicalpathologic features and reflects tumor biology. Decisions that rely solely on clinical-pathological factors may often lead to overtreatment and in these cases the information provided by multigene signatures may reduce the use of unnecessary adjuvant chemotherapy without increasing the risk of relapse. In contemporary management of HR+HER2- early BC clinical decisions regarding adjuvant systemic therapy should be made after considering both genomic results and clinicalpathological features. However, risk stratification according to clinical-pathological features still remains crucial and multigene signature assays should be used mostly for cases where clinicalpathological parameters do not clearly imply or oppose the benefit of chemotherapy.

\section{References}

1. Zadnik V, Primic Žakelj M. SLORA: Slovenija in rak. Epidemiologija in register raka. Ljubljana: Epidemiologija in register raka. Onkološki inštitut Ljubljana. [cited 2019 April 15]. Available at: http://www.slora.si.

2. Curigliano G, Burstein HJ, Winer E, Gnant M, Dubsky P, Loibl S, et al. Deescalating and escalating treatments for early-stage breast cancer: the St. Gallen International Expert Consensus Conference on the Primary Therapy of Early Breast Cancer 2017. Ann Oncol 2017; 28: 1700-12. doi: 10.1093/ annonc/mdx308
3. Peto R, Davies C, Godwin J, Gray R, Pan HC, Clarke M, et al. Comparisons between different polychemotherapy regimens for early breast cancer: metaanalyses of long-term outcome among 100,000 women in 123 randomised trials. Lancet 2012; 379: 432-44. doi: 10.1016/S0140-6736(11)61625-5

4. Early Breast Cancer Trialists' Collaborative Group (EBCTCG). Effects of chemotherapy and hormonal therapy for early breast cancer on recurrence and 15-year survival: an overview of the randomised trials. Lancet 2005; 365: 1687-717. doi: 10.1016/S0140-6736(05)66544-0

5. Mamounas EP, Russell CA, Lau A, Turner MP, Albain KS. Clinical relevance of the 21-gene Recurrence Score((R)) assay in treatment decisions for patients with node-positive breast cancer in the genomic era. NPJ Breast Cancer 2018; 4: 27. doi: 10.1038/s41523-018-0082-6

6. Duffy MJ, Harbeck N, Nap M, Molina R, Nicolini A, Senkus E, et al. Clinical use of biomarkers in breast cancer: Updated guidelines from the European Group on Tumor Markers (EGTM). Eur J Cancer 2017; 75: 284-98. doi: 10.1016/j.ejca.2017.01.017

7. Krop I, Ismaila N, Andre F, Bast RC, Barlow W, Collyar DE, et al. Use of biomarkers to guide decisions on adjuvant systemic therapy for women with early-stage invasive breast cancer: American Society of Clinical Oncology Clinical Practice Guideline Focused Update. J Clin Oncol 2017; 35: 2838-47. doi: 10.1200/JCO.2017.74.0472

8. Senkus E, Kyriakides S, Ohno S, Penault-Llorca F, Poortmans P, Rutgers E, et al. Primary breast cancer: ESMO clinical practice guidelines for diagnosis, treatment and follow-up. Ann Oncol 2015; 26 Suppl 5: v8-30. doi: 10.1093/ annonc/mdv298

9. National Comprehensive Cancer Network. NCCN Guidelines Version 1.2019 Breast Cancer.[cited 2019 June 6] Available at: ttps://www.nccn.org/professionals/physician_gls/pdf/breast.pdf.

10. Albain KS, Barlow WE, Shak S, Hortobagyi GN, Livingston RB, Yeh IT, et al. Prognostic and predictive value of the 21-gene recurrence score assay in postmenopausal women with node-positive, oestrogen-receptor-positive breast cancer on chemotherapy: a retrospective analysis of a randomised trial. Lancet Oncol 2010; 11: 55-65. doi: 10.1016/S1470-2045(09)70314-6

11. Paik S, Shak S, Tang G, Kim C, Baker J, Cronin M, et al. A multigene assay to predict recurrence of tamoxifen-treated, node-negative breast cancer. $N$ Engl J Med 2004; 351: 2817-26. doi: 10.1056/NEJMoa041588

12. Paik S, Tang G, Shak S, Kim C, Baker J, Kim W, et al. Gene expression and benefit of chemotherapy in women with node-negative, estrogen receptorpositive breast cancer. J Clin Oncol 2006; 24: 3726-34. doi: 10.1200/ JCO.2005.04.7985

13. Sparano JA, Gray RJ, Makower DF, Pritchard KI, Albain KS, Hayes DF, et al. Adjuvant chemotherapy guided by a 21-gene expression assay in breast cancer. N Engl J Med 2018; 379: 111-21. doi: 10.1056/NEJMoa1804710

14. Dowsett M, Cuzick J, Wale C, Forbes J, Mallon EA, Salter J, et al. Prediction of risk of distant recurrence using the 21-gene recurrence score in nodenegative and node-positive postmenopausal patients with breast cancer treated with anastrozole or tamoxifen: a TransATAC study. J Clin Oncol 2010; 28: 1829-34. doi: 10.1200/JCO.2009.24.4798

15. Simon RM, Paik S, Hayes DF. Use of archived specimens in evaluation of prognostic and predictive biomarkers. J Nat/ Cancer Inst 2009; 101: 1446-52. doi: 10.1093/jnci/djp335

16. Gluz O, Nitz UA, Christgen M, Kates RE, Shak S, Clemens M, et al. West German Study Group Phase III PlanB Trial: First prospective outcome data for the 21-gene recurrence score assay and concordance of prognostic markers by central and local pathology assessment. J Clin Oncol 2016; 34: 2341-9. doi: 10.1200/JCO.2015.63.5383

17. Roberts MC, Miller DP, Shak S, Petkov VI. Breast cancer-specific survival in patients with lymph node-positive hormone receptor-positive invasive breast cancer and Oncotype DX Recurrence Score results in the SEER database. Breast Cancer Res Treat 2017; 163: 303-10. doi: 10.1007/s10549-0174162-3

18. Stemmer SM, Steiner M, Rizel S, Geffen DB, Nisenbaum B, Peretz T, et al. Clinical outcomes in ER+ HER2 -node-positive breast cancer patients who were treated according to the Recurrence Score results: evidence from a large prospectively designed registry. NPJ Breast Cancer 2017; 3: 32. doi: $10.1038 / \mathrm{s} 41523-017-0033-7$

19. ClinicalTrials.gov. Tamoxifen Citrate, Letrozole, Anastrozole, or Exemestane With or Without Chemotherapy in Treating Patients With Invasive RxPONDER Breast Cancer. [cited 2019 July 11] Available at: https://clinicaltrials.gov/ct2/show/NCT01272037. 
20. van 't Veer L, Dai H, van de Vijver MJ, He YD, Hart AA, Mao M, et al. Gene expression profiling predicts clinical outcome of breast cancer. Nature 2002 415: 530-6. doi: 10.1038/415530a

21. Tian S, Roepman P, Van't Veer $\amalg$, Bernards R, de Snoo F, Glas AM. Biological functions of the genes in the mammaprint breast cancer profile reflect the hallmarks of cancer. Biomark Insights 2010; 5: 129-38. doi: 10.4137/BMI. S6184

22. van de Vijver MJ, He YD, van't Veer L, Dai H, Hart AA, Voskuil DW, et al. A gene-expression signature as a predictor of survival in breast cancer. $\mathrm{N}$ Eng J Med 2002; 347: 1999-2009. doi: 10.1056/NEJMoa021967

23. Buyse M, Loi S, van't Veer L, Viale G, Delorenzi M, Glas AM, et al. Validation and clinical utility of a 70-gene prognostic signature for women with nodenegative breast cancer. J Natl Cancer Inst 2006; 98: 1183-92. doi: 10.1093/ jnci/djj329

24. Sapino A, Roepman P, Linn SC, Snel MH, Delahaye $\amalg$, van den Akker J, et al. MammaPrint molecular diagnostics on formalin-fixed, paraffin-embedded tissue. J Mol Diagn 2014; 16: 190-7. doi: 10.1016/j.jmoldx.2013.10.008

25. Drukker CA, Bueno-de-Mesquita JM, Retel VP, van Harten WH, van Tinteren $\mathrm{H}$, Wesseling J, et al. A prospective evaluation of a breast cancer prognosis signature in the observational RASTER study. Int J Cancer 2013; 133: 929-36. doi: $10.1002 /$ ijc. 28082

26. Olivotto IA, Bajdik CD, Ravdin PM, Speers CH, Coldman AJ, Norris BD, et al. Population-based validation of the prognostic model ADJUVANT! for early breast cancer. J Clin Oncol 2005; 23: 2716-25. doi: 10.1200/JCO.2005.06.178

27. Mook S, Schmidt MK, Weigelt B, Kreike B, Eekhout I, van de Vijver MJ, et al. The 70-gene prognosis signature predicts early metastasis in breast cancer patients between 55 and 70 years of age. Ann Oncol 2010; 21: 717-22. doi: 10.1093/annonc/mdp388

28. Bogaerts J, Cardoso F, Buyse M, Braga S, Loi S, Harrison JA, et al. Gene signature evaluation as a prognostic tool: challenges in the design of the MINDACT trial. Nat Clin Pract Oncol 2006; 3: 540-51. doi: 10.1038/ ncponc0591

29. Cardoso F, Van't Veer L, Rutgers E, Loi S, Mook S, Piccart-Gebhart MJ. Clinical application of the 70-gene profile: the MINDACT trial. J Clin Oncol 2008; 26 729-35. doi: 10.1200/JCO.2007.14.3222

30. Cardoso F, van't Veer $\sqcup$, Bogaerts J, Slaets L, Viale G, Delaloge S, et al. 70-Gene signature as an aid to treatment decisions in early-stage breast cancer. N Engl J Med 2016; 375: 717-29. doi: 10.1056/NEJMoa1602253

31. Esserman $\sqcup$, Yau C, Thompson CK, van 't Veer $\sqcup$, Borowsky AD, Hoadley $\mathrm{KA}$, et al. Use of molecular tools to identify patients with indolent breast cancers with ultralow risk over 2 decades. JAMA Oncol 2017; 3: 1503-10. doi: 10.1001/jamaoncol.2017.1261

32. Dubsky P, Brase JC, Jakesz R, Rudas M, Singer CF, Greil R, et al. The EndoPredict score provides prognostic information on late distant metastases in ER+/HER2- breast cancer patients. Br J Cancer 2013; 109: 2959-64. doi: $10.1038 /$ bjc. 2013.671

33. Filipits $M$, Rudas $M$, Jakesz $R$, Dubsky $P$, Fitzal F, Singer $C F$, et al. A new molecular predictor of distant recurrence in ER-positive, HER2-negative breast cancer adds independent information to conventional clinical risk factors. Clin Cancer Res 2011; 17: 6012-20. doi: 10.1158/1078-0432.CCR-11-0926

34. Parker JS, Mullins M, Cheang MC, Leung S, Voduc D, Vickery T, et al. Supervised risk predictor of breast cancer based on intrinsic subtypes. J Clin Oncol 2009; 27: 1160-7. doi: 10.1200/JCO.2008.18.1370

35. Gnant M, Filipits M, Greil R, Stoeger H, Rudas M, Bago-Horvath Z, et al. Predicting distant recurrence in receptor-positive breast cancer patients with limited clinicopathological risk: using the PAM50 Risk of Recurrence score in 1478 postmenopausal patients of the ABCSG-8 trial treated with adjuvant endocrine therapy alone. Ann Oncol 2014; 25: 339-45. doi: 10.1093/annonc/mdt494

36. Jerevall PL, Ma XJ, Li H, Salunga R, Kesty NC, Erlander MG, et al. Prognostic utility of HOXB13:IL17BR and molecular grade index in early-stage breast cancer patients from the Stockholm trial. Br J Cancer 2011; 104: 1762-9. doi: 10.1038/bjc.2011.145

37. Sgroi DC, Carney E, Zarrella E, Steffel L, Binns SN, Finkelstein DM, et al. Prediction of late disease recurrence and extended adjuvant letrozole benefit by the HOXB13/IL17BR biomarker. I Natl Cancer Inst 2013; 105: 1036-42. doi: 10.1093/jnci/djt146
38. Dowsett M, Sestak I, Lopez-Knowles E, Sidhu K, Dunbier AK, Cowens JW, et al. Comparison of PAM50 risk of recurrence score with oncotype DX and IHC4 for predicting risk of distant recurrence after endocrine therapy. I Clin Oncol 2013; 31: 2783-90. doi: 10.1200/JCO.2012.46.1558

39. Harbeck N, Thomssen C. A new look at node-negative breast cancer Oncologist 2011; 16 Suppl 1: 51-60. doi: 10.1634/theoncologist.2011-S1-51

40. Mook S, Schmidt MK, Viale G, Pruneri G, Eekhout I, Floore A, et al. The 70-gene prognosis-signature predicts disease outcome in breast cancer patients with 1-3 positive lymph nodes in an independent validation study. Breast Cancer Res Treat 2009; 116: 295-302. doi: 10.1007/s10549-0080130-2

41. Chang MC, Souter LH, Kamel-Reid S, Rutherford M, Bedard P, Trudeau M, et al. Clinical utility of multigene profiling assays in early-stage breast cancer. Curr Oncol 2017; 24: e403-e22. doi: 10.3747/co.24.3595

42. Clark GM. Prognostic factors versus predictive factors: Examples from a clinical trial of erlotinib. Mol Oncol 2008; 1: 406-12. doi: 10.1016/j.molonc.2007.12.001

43. Ballman KV. Biomarker: Predictive or Prognostic? J Clin Oncol 2015; 33: 3968-71. doi: 10.1200/JCO.2015.63.3651

44. Bhutiani N, Egger ME, Ajkay N, Scoggins CR, Martin RC, 2nd, McMasters KM. Multigene signature panels and breast cancer therapy: patterns of use and impact on clinical decision making. J Am Coll Surg 2018; 226: 406-12 e1. doi: 10.1016/j.jamcollsurg.2017.12.043

45. Petkov VI, Miller DP, Howlader N, Gliner N, Howe W, Schussler N, et al. Breast-cancer-specific mortality in patients treated based on the 21-gene assay: a SEER population-based study. NPJ Breast Cancer 2016; 2: 16017. doi: 10.1038/npjbcancer.2016.17

46. Su KW, Hall J, Soulos PR, Abu-Khalaf MM, Evans SB, Mougalian SS, et al. Association of 21-gene recurrence score assay and adjuvant chemotherapy use in the medicare population, 2008-2011. J Geriatr Oncol 2016; 7: 15-23. doi: 10.1016/j.jgo.2015.11.002

47. Potosky AL, O'Neill SC, Isaacs C, Tsai HT, Chao C, Liu C, et al. Populationbased study of the effect of gene expression profiling on adjuvant chemotherapy use in breast cancer patients under the age of 65 years. Cancer 2015; 121: 4062-70. doi: 10.1002/cncr.29621

48. Hassett MJ, Silver SM, Hughes ME, Blayney DW, Edge SB, Herman JG, et al. Adoption of gene expression profile testing and association with use of chemotherapy among women with breast cancer. J Clin Oncol 2012; 30: 2218-26. doi: 10.1200/JCO.2011.38.5740

49. Blok EJ, Bastiaannet E, van den Hout WB, Liefers GJ, Smit V, Kroep JR, et al. Systematic review of the clinical and economic value of gene expression profiles for invasive early breast cancer available in Europe. Cancer Treat Rev 2018; 62: 74-90. doi: 10.1016/j.ctrv.2017.10.012

50. Sestak I, Buus R, Cuzick J, Dubsky P, Kronenwett R, Denkert C, et al. Comparison of the performance of 6 prognostic signatures for estrogen receptor-positive breast cancer: a secondary analysis of a randomized clinical trial. JAMA Oncol 2018; 4: 545-53. doi: 10.1001/jamaoncol.2017.5524

51. Bartlett JM, Bayani J, Marshall A, Dunn JA, Campbell A, Cunningham C, et al. Comparing breast cancer multiparameter tests in the OPTIMA prelim trial: no test is more equal than the others. J Natl Cancer Inst 2016; 108: pii: djw050. doi: 10.1093/jnci/djw050 